\title{
Multivariable statistical analysis of spectrophotometry and spectra of (162173) Ryugu as observed by JAXA Hayabusa2 mission
}

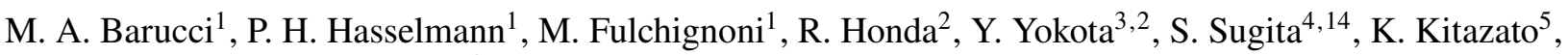 \\ J. D. P. Deshapriya ${ }^{1}$, D. Perna ${ }^{6,1}$, E. Tatsumi ${ }^{4,19}$, D. Domingue ${ }^{17}$, T. Morota ${ }^{7}$, S. Kameda ${ }^{8}$, T. Iwata ${ }^{3,17}$, \\ M. Abe ${ }^{3,17}$, M. Ohtake ${ }^{3,17}$, S. Matsuura ${ }^{9}$, M. Matsuoka ${ }^{3}$, T. Hiroi ${ }^{10}$, T. Nakamura' ${ }^{11}$, T. Kouyama ${ }^{12}$, H. Suzuki ${ }^{13}$, \\ M. Yamada ${ }^{14}$, N. Sakatani ${ }^{3}$, C. Honda ${ }^{5}$, K. Ogawa ${ }^{15}$, M. Hayakawa ${ }^{3}$, K. Yoshioka ${ }^{4}$, Y. Cho ${ }^{4}$, H. Sawada ${ }^{3}$, D. Takir ${ }^{16}$,

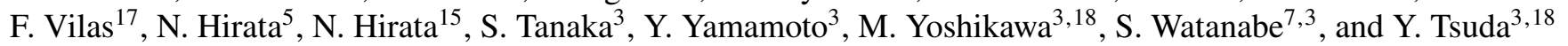

(Affiliations can be found after the references)

Received 6 May 2019 / Accepted 4 July 2019

\begin{abstract}
Context. Starting from late June 2018, the JAXA asteroid sample return mission Hayabusa2 acquired a large quantity of resolved images and spectra of the surface of the asteroid (162173) Ryugu.

Aims. By studying the visible and near-infrared spectral behavior across the surface of Ryugu using a statistical analysis, we aim to distinguish spectral homogeneous groups and to detect the small heterogeneities. This allows us to better constrain the surface composition variations.

Methods. In order to isolate and interpret the difference in the asteroid surface spectral behavior, we applied the $G$-mode multivariate statistical analysis to a set of pixels containing information of (i) the visible ONC-T spectrophotometry, and (ii) the near-infrared NIRS3 spectra thereby obtaining automatic statistical clustering at different confidence levels.

Results. The analysis of both ONC-T and NIRS3 data allows us to highlight small spectral variations on the Ryugu surface. At a $3 \sigma$ confidence level, only two groups are evident, while going down to $2 \sigma$ more groups are obtained with differences in spectral slope and band depth.

Conclusions. The identified groups have been associated with main morphological surface features. The spectral slope variations that characterize the small groups obtained by ONC-T data analysis, are interpreted as a consequence of space weathering with the presence of more or less fresh material and/or the different grain sizes of the regolith. The variations found analyzing the NIRS3 data are attributed to slightly different contents of hydrated material and different regolith sizes. The distribution on the Ryugu surface of the groups obtained by the analysis of the two instruments indicates a clear spectral dichotomy both between the east and west, and the north and south hemispheres. Small sized regolith grains associated to the redder spectra seem concentrated in the southwestern part of the body.
\end{abstract}

Key words. minor planets, asteroids: individual: RYUGU - methods: statistical - techniques: photometric techniques: spectroscopic

\section{Introduction}

The Hayabusa2 JAXA asteroid sample return mission was launched on December 3, 2014 and recently arrived to the primitive asteroid (162173) Ryugu after 3.5 yr of cruise. On June 27, 2018 the spacecraft was set at $20 \mathrm{~km}$ from Ryugu's surface (called "home position") hovering the asteroid in order to start the initial mapping phase. At that time the Hayabusa 2 mission acquired a very large number of resolved images and spectra of the asteroid surface. The on-board instruments reveal Ryugu as a top-shape body characterized by an equatorial ridge with a radius of $502 \pm 2 \mathrm{~m}$, and a very low density of $1190 \pm 3 \mathrm{~kg} \mathrm{~m}^{-3}$. This implies porosity larger than $50 \%$ and a rubble-pile nature (Watanabe et al. 2019). Ryugu presents a very dark surface with the visible geometric albedo of $0.045 \pm 0.002$ (Sugita et al. 2019).

Two instruments, the optical navigation camera (ONC-T) and the near-infrared spectrometer (NIRS3) are devoted to investigating the surface composition variations mapping the complete surface of Ryugu (Kameda et al. 2017; Suzuki et al. 2018;
Iwata et al. 2017). The asteroid shows a surface rich in geological structures (craters, boulders of different size, texture, ridges, depressions, troughs, etc.). The largest boulder, Otohime Saxum, located near the south pole has a dimension of about $160 \mathrm{~m}$ (Sugita et al. 2019). The telescopic ONC-T obtained spectrophotometric data by imaging Ryugu with seven broadband filters spanning from 398 to $946 \mathrm{~nm}$ at different surface resolutions.

NIRS3 acquired reflectance spectra in the wavelength range from 1800 to $3200 \mathrm{~nm}$ operating in scanning mode (Kitazato et al. 2019). The spectral data show a weak positive spectral slope in the first part of the spectra and a clear weak narrow absorption band at $2720 \mathrm{~nm}$, detected across the entire observed surface. The absorption band indicates the presence of $\mathrm{OH}$-bearing minerals all over the surface, associated to $\mathrm{Mg}$-rich phyllosilicates (Kitazato et al. 2019). No meteoritic samples seem to have reflectance spectra to perfectly match those of Ryugu's surface that were obtained at the same wavelengths. Possible similarities have been found with the spectra of thermally-metamorphosed CI chondrites and shocked CM chondrites. 
The spectral and spectrophotometric data show an almost homogeneous surface with small variations (Kitazato et al. 2019; Sugita et al. 2019). In the present work we used a multivariate statistical method to separately analyze the ONC-T broadband filters and the NIRS3 spectral data in order to characterize possible spectrophotometric and spectroscopic heterogeneities of the Ryugu surface and to compare them with morphological surface structures. Our investigation was part of a detailed analysis conducted to study in greater depth any possible small surface compositional variations and to support the landing and sampling sites selection (Yabuta et al. 2019).

\section{Data analysis}

\subsection{Data}

We used the ONC-T data obtained on July 12, 2018 at $20 \mathrm{~km}$ altitude, which have almost global coverage at a resolution of $2 \mathrm{~m} \mathrm{pixel}^{-1}$. We used the normalized reflectance measured in the seven broadband filters $(u l=397.5 \mathrm{~nm} ; b=479.8 \mathrm{~nm}$; $v=548.9 \mathrm{~nm}, \quad n=589.9 \mathrm{~nm} ; \quad w=700.1 \mathrm{~nm} ; \quad x=857.3 \mathrm{~nm} ;$ and $p=945.1 \mathrm{~nm}$ ) with calibration and errors as reported by Tatsumi et al. (2019). The data have been coregistered as described by Honda et al. (2018, 2019) and photometrically corrected following the Hapke photometric model obtained for ONC-T $v$-filter images combined with ground-based observations as described by Sugita et al. (2019). Since the model parameters for the other band filters are still under examination (Domingue et al. 2019), the other filter images are also calibrated using this single photometric model. The data with emission and incidence angles larger than $50^{\circ}$ have been eliminated to avoid shadow effects. Then the mean value of a $5 \times 5$ pixel area (about $10 \times 10 \mathrm{~m}$ ) is calculated to reduce noise. The ONC-T data were also analyzed by Honda et al. (2019) using different clustering methods.

For the NIRS3 data, we used the spectra collected on July 11 and July 19, 2018 which allowed us to obtain near-global coverage at a spatial resolution of 40 and $20 \mathrm{~m} \mathrm{px}^{-1}$, respectively. We also analyzed the spectral data of October 30, 2018, which cover the equatorial ridge of the asteroid Ryugu at a higher resolution of about $10 \mathrm{~m} \mathrm{px}^{-1}$. These observations were carried out at phase angles of $18.2^{\circ}, 17.5-17.8^{\circ}$, and $7.6-7.8^{\circ}$ respectively. The NIRS3 data were thermally and photometrically corrected as described in Kitazato et al. (2019). The variations of the spectra are very small and concern essentially the slope between 2000 and $2600 \mathrm{~nm}$ though variation also occurs slightly at a band depth of $2720 \mathrm{~nm}$ with no variation on the position of the central band. Consequently we selected 24 wavelengths (variables, as defined in the next Sect. 2.2) between those that are more significative in the spectral range of 1900 and $2900 \mathrm{~nm}$, excluding the part of the spectra with higher signal-to-noise ratio $(\mathrm{S} / \mathrm{N})$. Eight variables were selected in the wavelength range 1900-2600 nm to represent the slope and all the channels for the $2600-2900 \mathrm{~nm}$ to take into consideration all band variations (see the first column of Table 2).

\subsection{The G-mode multivariate statistical method}

In order to investigate the compositional surface variation of the asteroid Ryugu, we applied the $G$-mode multivariate statistical analysis (Coradini et al. 1977; Gavrishin et al. 1992) to the data described above. The $G$-mode method has been widely used in the planetary field to classify asteroids (Barucci et al. 1987; Fulchignoni et al. 2000; Hasselmann et al. 2013), transneptunian objects (Barucci et al. 2005; Belskaya et al. 2015), and to search for variations in the surface composition of the asteroid Steins (Leyrat et al. 2010) and on the comet 67P (Perna et al. 2017) in order to analyze the images taken with different filters by the Rosetta's OSIRIS camera (Keller et al. 2007).

This method allows the user to obtain an automatic statistical clustering of a sample containing $N$ objects (in this work the pixels) described by $M$ variables (the normalized reflectance of each filter for the ONC-T data and of a selected set of wavelength channels for the NIRS3 data) in terms of homogeneous groups without any a priori criteria and taking into account the instrumental errors in measuring each variable. The $G$-mode analysis separates the sample of $N$ objects into $J$ homogeneous groups. Each object is described by $M$ variables $i(i=1, \ldots, M)$. The data are arranged in a $N \times M$ matrix, the mean value $\left(\bar{x}_{i}\right)$ and the variance $\left(\sigma_{i}^{2}\right)$ for each variable, and the $M \times M$ correlation matrix of the variables were computed. Each object will then be represented by a new variable $z_{j}^{2}$

$z_{j}^{2}=\sum_{i=1}^{M} z_{i j}^{2}=\sum_{i=1}^{M} \frac{\left(x_{i j}^{2}-\bar{x}_{i}^{2}\right)}{\sigma_{i}^{2}}$,

where $x_{i j}$ is the $i$ th variable of the $j$ th sample. When $x_{i j}$ are independent and normally distributed, $z_{j}^{2}$ follow a $\chi^{2}$ distribution with $M$ degrees of freedom (Miller \& Khan 1962). If $x_{i j}$ are not independent, the dependence of the variables is represented by

$R=\frac{M}{\sum_{k, m=1}^{M} r_{k, m}}$

where $r_{k, m}$ are the elements of the correlation matrix. The $z_{j}^{2}$ variable is then defined as

$z_{j}^{2}=R \cdot \sum_{i=1}^{M} z_{i j}^{2}$

and it follows a $\chi^{2}$ distribution with $f=N \times M \times R$ degrees of freedom (Bagrov 1978) that can be transformed (Abramowitz \& Stegun 1972) in a standard normal distribution by the parameter

$g_{j}=\sqrt{2 \cdot z_{j}^{2}}-\sqrt{2 f-1}$.

An iterative procedure based on a test of the hypothesis of appurtenance of the jth object to a "zero group" allows the user to identify homogeneous groups of objects. This zero group (the starter of the procedure) is defined as the sum of the three closer objects (those having the minimum value of $z$ ),

$z_{p, q, t}=\min \left(\sum_{i=1}^{M}\left[\left(z_{p i}-z_{q i}\right)^{2}+\left(z_{p i}-z_{t i}\right)^{2}+\left(z_{q i}-z_{t i}\right)^{2}\right]\right)$,

where $z_{p i}, z_{q i}$, and $z_{t i}$ are the normalized values of the $i$ th variable of the $p$ th, $q$ th, and $t$ th objects, respectively. The mean value and the variance of each variable are computed for these three objects

$$
\bar{x}_{j *}=\frac{1}{3} \cdot \sum_{j=1}^{3} x_{i j} \quad \sigma_{i *}^{2}=\frac{1}{2} \cdot \sum_{i=1}^{3}\left(x_{i j}^{2}-\bar{x}_{i *}^{2}\right) .
$$

The values of $z_{j}^{2}, f$, and $g_{j}$ were recomputed substituting the values obtained in Eq. (1) into Eqs. (1)-(3), and the value given 
M. A. Barucci et al.: Spectral variations on the Ryugu's surface

Table 1. Mean values of the reflectance normalized at $v$ filter and relative standard deviations of each group as obtained with both analyses at both confidence level values ( $3 \sigma$ and $2 \sigma)$.

\begin{tabular}{|c|c|c|c|c|c|c|c|c|}
\hline Confidence level & $3 \sigma$ & $3 \sigma$ & $2 \sigma$ & $2 \sigma$ & $2 \sigma$ & $2 \sigma$ & $2 \sigma$ & $2 \sigma$ \\
\hline & $\begin{array}{l}\text { Group } \\
\# 1\end{array}$ & $\begin{array}{l}\text { Group } \\
\# 2\end{array}$ & $\begin{array}{l}\text { Group } \\
\# 1\end{array}$ & $\begin{array}{l}\text { Group } \\
\# 2\end{array}$ & $\begin{array}{l}\text { Group } \\
\# 3\end{array}$ & $\begin{array}{l}\text { Group } \\
\# 4\end{array}$ & $\begin{array}{l}\text { Group } \\
\# 5\end{array}$ & $\begin{array}{l}\text { Group } \\
\# 6\end{array}$ \\
\hline Numbers of sample & 35840 & 1014 & 33550 & 1993 & 531 & 201 & 71 & 129 \\
\hline \multicolumn{9}{|l|}{ Wavelength (nm) } \\
\hline$u l=397.5$ & $\begin{array}{l}1.0495 \\
\pm 0.01 \\
\end{array}$ & $\begin{array}{l}1.0428 \\
\pm 0.0271 \\
\end{array}$ & $\begin{array}{l}1.0493 \\
\pm 0.0096 \\
\end{array}$ & $\begin{array}{l}1.0493 \\
\pm 0.0157 \\
\end{array}$ & $\begin{array}{l}1.0588 \\
\pm 0.0109 \\
\end{array}$ & $\begin{array}{l}1.0249 \\
\pm 0.0059 \\
\end{array}$ & $\begin{array}{l}1.0320 \\
\pm 0.0047 \\
\end{array}$ & $\begin{array}{l}1.0556 \\
\pm 0.0091 \\
\end{array}$ \\
\hline$b=479.8$ & $\begin{array}{l}0.9916 \\
\pm 0.0056\end{array}$ & $\begin{array}{l}0.9865 \\
\pm 0.0229\end{array}$ & $\begin{array}{l}0.9917 \\
\pm 0.0052\end{array}$ & $\begin{array}{l}0.9911 \\
\pm 0.0109\end{array}$ & $\begin{array}{l}0.9989 \\
\pm 0.0068\end{array}$ & $\begin{array}{l}0.9735 \\
\pm 0.0039\end{array}$ & $\begin{array}{l}0.9833 \\
\pm 0.0023\end{array}$ & $\begin{array}{l}1.0021 \\
\pm 0.0083\end{array}$ \\
\hline$n=589.9$ & $\begin{array}{l}1.0041 \\
\pm 0.0044\end{array}$ & $\begin{array}{l}0.9954 \\
\pm 0.0139\end{array}$ & $\begin{array}{l}1.0043 \\
\pm 0.0041\end{array}$ & $\begin{array}{l}0.9983 \\
\pm 0.0059\end{array}$ & $\begin{array}{l}1.0138 \\
\pm 0.0029\end{array}$ & $\begin{array}{l}0.9940 \\
\pm 0.0029\end{array}$ & $\begin{array}{l}1.0045 \\
\pm 0.0022\end{array}$ & $\begin{array}{l}0.9975 \\
\pm 0.0050\end{array}$ \\
\hline$w=700.1$ & $\begin{array}{l}1.0069 \\
\pm 0.0053\end{array}$ & $\begin{array}{l}0.9942 \\
\pm 0.0117\end{array}$ & $\begin{array}{l}1.0071 \\
\pm 0.0048\end{array}$ & $\begin{array}{l}0.9958 \\
\pm 0.0039\end{array}$ & $\begin{array}{l}1.0179 \\
\pm 0.0042\end{array}$ & $\begin{array}{l}1.0062 \\
\pm 0.0034\end{array}$ & $\begin{array}{l}1.0168 \\
\pm 0.0018\end{array}$ & $\begin{array}{l}0.9810 \\
\pm 0.0053\end{array}$ \\
\hline$x=857.3$ & $\begin{array}{l}1.0335 \\
\pm 0.0094\end{array}$ & $\begin{array}{l}1.0115 \\
\pm 0.0219\end{array}$ & $\begin{array}{l}1.0340 \\
\pm 0.0084\end{array}$ & $\begin{array}{l}1.0128 \\
\pm 0.0080\end{array}$ & $\begin{array}{l}1.0495 \\
\pm 0.0071\end{array}$ & $\begin{array}{l}1.0375 \\
\pm 0.0058\end{array}$ & $\begin{array}{l}1.0558 \\
\pm 0.0030\end{array}$ & $\begin{array}{l}0.9809 \\
\pm 0.0113\end{array}$ \\
\hline$p=945.1$ & $\begin{array}{l}1.0043 \\
\pm 0.01\end{array}$ & $\begin{array}{l}0.9766 \\
\pm 0.0274\end{array}$ & $\begin{array}{l}1.005 \\
\pm 0.0097\end{array}$ & $\begin{array}{l}0.9792 \\
\pm 0.0085\end{array}$ & $\begin{array}{l}1.0257 \\
\pm 0.0072\end{array}$ & $\begin{array}{l}1.0047 \\
\pm 0.0075\end{array}$ & $\begin{array}{l}1.0278 \\
\pm 0.0036\end{array}$ & $\begin{array}{l}0.941 \\
\pm 0.0147\end{array}$ \\
\hline Reflectance at $v=548.9$ & $\begin{array}{l}0.0189 \\
\pm 0.0009\end{array}$ & $\begin{array}{l}0.0202 \\
\pm 0.0059\end{array}$ & $\begin{array}{l}0.0189 \\
\pm 0.00085\end{array}$ & $\begin{array}{l}0.0195 \\
\pm 0.0019\end{array}$ & $\begin{array}{l}0.0181 \\
\pm 0.00385\end{array}$ & $\begin{array}{l}0.0198 \\
\pm 0.0066\end{array}$ & $\begin{array}{l}0.0187 \\
\pm 0.0007\end{array}$ & $\begin{array}{l}0.0214 \\
\pm 0.0028\end{array}$ \\
\hline
\end{tabular}

Notes. In the first column, the ONC-T central filter wavelengths are reported. The second and third columns report the mean values of the two groups obtained at $3 \sigma$, while in the other columns show the groups obtained at $2 \sigma$. The number of sample for each group is listed. In the last line the mean reflectance was computed for each group obtained and its standard deviation is also reported.

by Eq. (4) is compared with a critical value q1 selected a priori. Thus, we test the hypothesis of appurtenance of a given object described by its $g_{j}$ value to the group defined by Eq. (6). $N^{\prime}$ objects with $g_{j}<\mathrm{q} 1$ are considered as belonging to the same homogeneous group. The values of the mean and the variance of these $N^{\prime}$ objects were computed and a new iteration was started using these values in the Eqs. (1)-(4). The iterations were stopped when $N^{\prime}$ and $R$ do not change in two successive cycles. The same procedure was then applied to the remaining $N-N^{\prime}$ objects and the grouping was continued until the number of objects left was less than three. The user can select the confidence level that corresponds to a given critical value q1: the larger the $\mathrm{q} 1$, the less detailed the classification. If the user wants to classify the whole sample with a $99.7 \%$ probability of making the right decision in inserting a sample in a group, the critical value of q1 has to be 3.00, which is the value corresponding to the $3 \sigma$ level of a standardized normal distribution (i.e., a probability of $0.3 \%$ of misclassifying an object). In choosing a lower confidence level, the probability of making a wrong decision increases, but it is possible to have a more detailed grouping. The method also gives indications on the relative importance of the variables in separating the groups. For a detailed description of the method, we refer the reader to the aforementioned literature (e.g. Barucci et al. 1987).

\section{Results}

\subsection{ONC-T data analysis}

We analyzed the data obtained on July 12, 2018 consisting in the spectrophotometric behavior of 36875 pixels (covering about $95 \%$ of the asteroid surface) described by the reflectance values measured through the above defined filters (Table 1, first column) and normalized to the $v$ filter reflectance (centered at $549 \mathrm{~nm}$ ). We started our analysis by choosing a confidence level $3 \sigma$ and we obtained a splitting of our sample into two groups (Fig. 1a), separated essentially by the reflectance values at larger wavelengths. The first group contains most of the pixels (97\%). The smaller group contains the pixels whose spectrophotometric behavior is distinguished from that of the bulk of the sample.

The slope of the average spectrum between 549 and $857 \mathrm{~nm}$ of the smaller group is quite neutral, while that of the bigger one is lightly redder. Both groups have a decrease at $945 \mathrm{~nm}$. This result indicates a strong homogeneity of the spectrophotometric data. The choice of the $3 \sigma$ confidence level is too conservative owing to the global uniformity of the data. Thus we started to decrease the confidence level and found that only at a confidence level of $2 \sigma$ do more small groups separate from the larger one, mainly by the reflectance values at 700,857 , and $945 \mathrm{~nm}$, which contribute in characterizing different small areas. The $2 \sigma$ confidence level implies a probability of incorrect classification of about $2.3 \%$. In Table 1 the mean values and the standard deviations of each group obtained at both values of confidence levels are reported.

The average spectral behavior of the six identified groups, presented in Fig. 1b, shows a band at $487 \mathrm{~nm}$, a drop of the reflectance at $945 \mathrm{~nm}$, and quite flat spectra with slopes between these two wavelengths, ranging from 0.011 to $0.021 \% / \mathrm{nm}$. The two larger groups (numbers 1 and 2, in Fig. 1b) are those already found at the $3 \sigma$ confidence level conserving the same spectrophotometric behavior. However, several objects have migrated from the larger group (\#1 in Fig. 1a) to double the population of the smaller one (\#2, which now includes about $5 \%$ of the objects) and to form four new small groups (containing each around $1 \%$ 


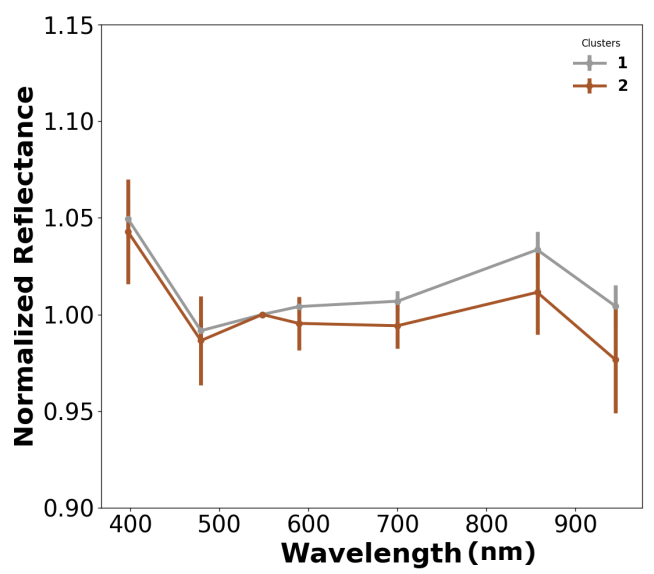

(a)

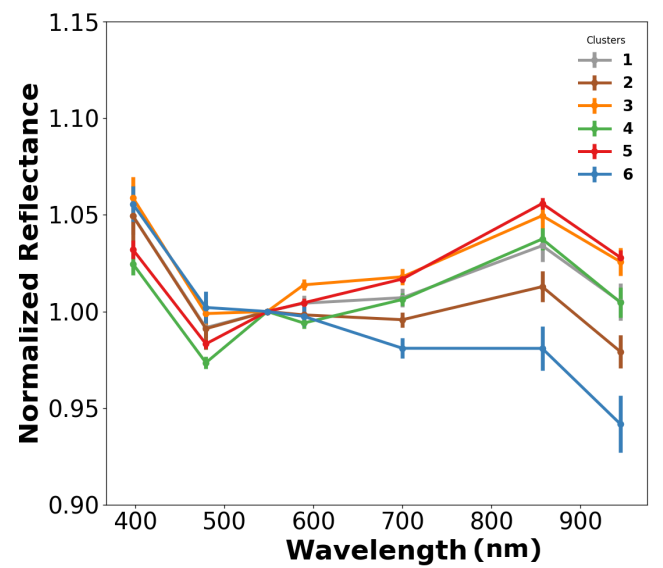

(b)

Fig. 1. Average value of variables in groups obtained with ONC-T data analysis. Values are the following: panel a: average spectra normalized to reflectance at $548.9 \mathrm{~nm}$ correspond to the two groups obtained with a $3 \sigma$ confidence level; and panel $b$ : average spectra normalized to reflectance at $548.9 \mathrm{~nm}$ correspond to the six groups obtained with a $2 \sigma$ confidence level. The error bar corresponds to the standard deviation of the distribution of the objects in each group.

of the objects) and reported in Fig. 1b. These new small groups are very well defined, following the very small value of their standard deviation and they may represent some specific characters of the asteroid surface. The new groups \#3 and \#5 are distinguished for the values between 397, 479, and $590 \mathrm{~nm}$, but, being redder, have the same slope trend in the range 700 and $947 \mathrm{~nm}$. Group \#4 has the same behavior as \#1 in the red part, but is very different in the ultraviolet, both the blue and visible parts, having the deepest band at $487 \mathrm{~nm}$. Group \#6 is the bluest and has a negative spectral slope.

\subsection{ONC-T map group distribution}

The different groups obtained are reported in maps as shown in Fig. 2 using the same color code for the spectra and compared with the map of Ryugu obtained by Sugita et al. (2019). The first group identified at $3 \sigma$ confidence level is shown in Fig. 2a and contains the majority of the observed area in that data $(97 \%)$. The second group, relatively small (only about $3 \%$ of the total data) is localized in the equatorial ridge, in some borders like Ejima and Otohime Saxum and inside some craters like Momotaro, Kibidango, and Cendrillon.

At the lower confidence level $2 \sigma$, as mentioned, we identified six main groups. The major group \#1, shown in the map (Fig. 2b) continues to represent almost the whole observed surface $(90 \%)$ of Ryugu, confirming homogeneity of the surface composition. Group \#2, shown in Fig. 2b increases, doubling the pixel number that is always present in the same areas, particularly in the Tokoyo Fossa on the equatorial ridge, and some other particular areas. Groups \#3 and \#5, redder in spectra, are more concentrated in areas with the presence of larger boulders, and around Ejima Saxum in the west and particularly in southern regions. Group \#4 is localized mainly in a few specific areas of the northern hemisphere, and particularly on the border of Cendrillon crater, while group \#6 with its bluer spectra is concentrated in the Otohime Saxum. The various groups correspond to the major morphological features as represented in the map of Fig. 2b. For more morphological details see the map from Sugita et al. (2019). As the quality of the data decreases near the pole, in particular the photometric correction due to different geometry, it becomes particularly difficult to evaluate this part of the surface.

\subsection{NIRS3 data analysis}

The analysis of NIRS3 data also confirms general spectral homogeneity on the Ryugu surface. For our analysis we included 24 variables (wavelengths reported in the first column of Table 2), selected between those more significative for slope and band variations, eliminating the wavelengths with higher uncertainties. The analysis of the data of July 11 (8300 spectra) and those of July 19 (13 385 spectra) at $3 \sigma$ confidence level gave the same results with two groups (Figs. 3a and c), which are distinguishable essentially in the spectral slope between 2200 and $2600 \mathrm{~nm}$ and slightly in the $2720 \mathrm{~nm}$ band depth. The first group concerns the majority of the measured surface (about 97\%) and the second one (which is much smaller) contains less than $3 \%$ of the obtained spectra. The average spectrum of the smaller group is redder than that of the larger group (see the mean values reported for each variable in Table 2 for $3 \sigma$ ).

A finer subdivision has been obtained for both the above quoted data sets when the confidence level is settled at $2 \sigma$. Almost identical results have been obtained for the analysis of July 11 and July 19 . Five groups are found, distinguished by their different slopes (between 2200 and $2600 \mathrm{~nm}$ ). The first group contains most of the spectra (83-84\%), three other groups (with respectively the 10,3 , and $1 \%$ of the spectra) have redder spectra, while the fourth group (2\%) has a less red behavior. The depth of the band at $2720 \mathrm{~nm}$ also affects the separation in the different groups. As shown in Figs. $3 \mathrm{a}$ and $\mathrm{c}$ and Table 2, the first and second groups obtained at $3 \sigma$ are almost the same as those of groups \#1 and \#3 obtained at the $2 \sigma$ confidence level (Figs. $3 b$ and $d$ ). The distribution of the slope of each of the five groups and the relative areas of the band at $2720 \mathrm{~nm}$ is reported in the histogram of Fig. 4 (a and b, respectively). As the results of the analysis of July 11 and July 19 are almost the same, we reported in Table 2 only the mean values of each group obtained with the analysis of July 19 data.

The spectra acquired on October 30 were collected closer to the asteroid, and constitute a data set (16528 spectra) with a higher resolution (about $10 \mathrm{~m} \mathrm{px}^{-1}$ ) with respect to those of July 11 and 19 . This implies much smaller coverage of the asteroid surface concentrate along the equator between $20^{\circ}$ and $-40^{\circ}$ latitudes. The analysis of this data set at the $3 \sigma$ level always shows the separation of the sample in the same two groups found 
(a)

ONC 07/12/2018 spectra_normalized $q 1=3.00$
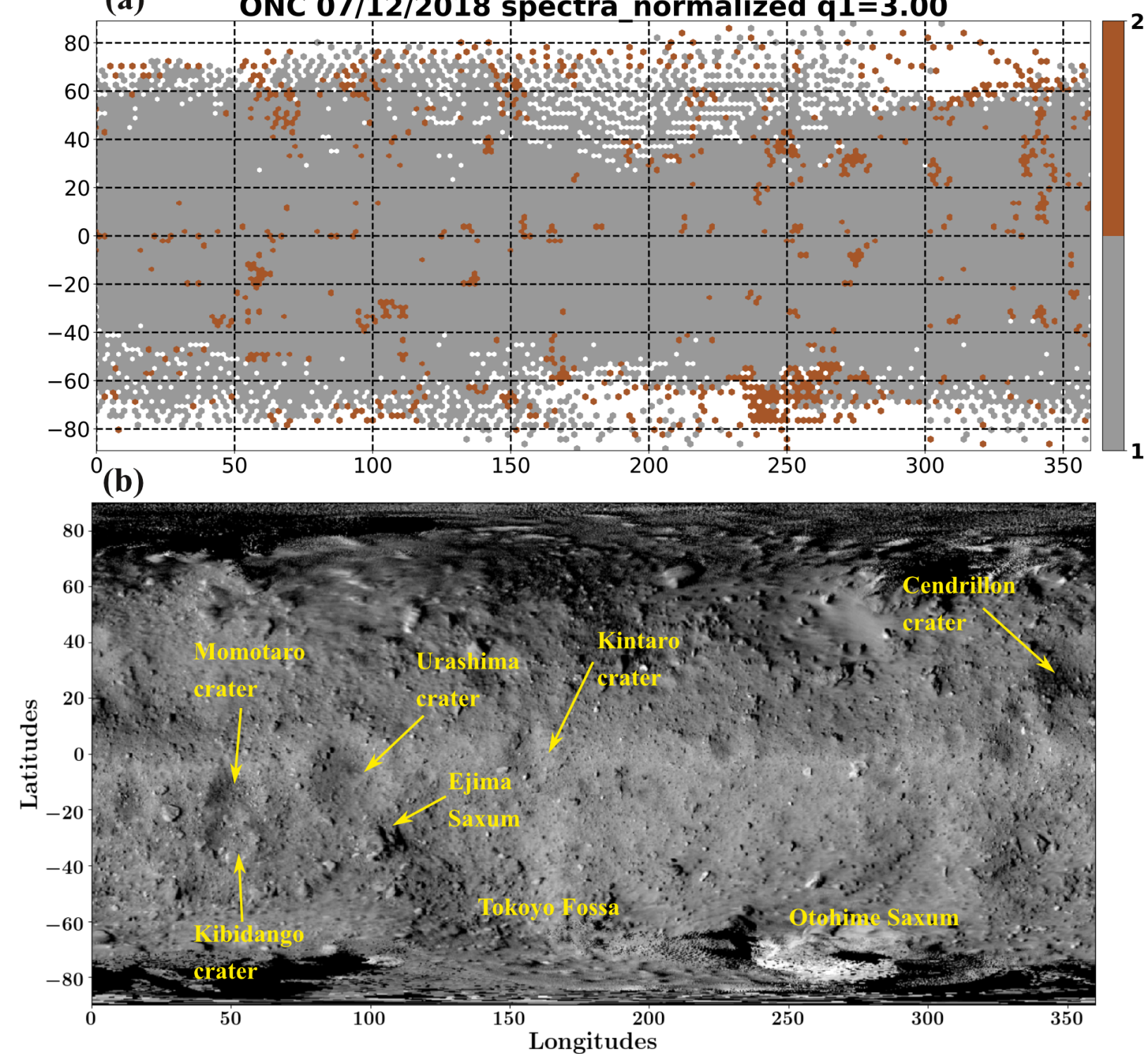

(c) ONC 07/12/2018 spectra_normalized $q 1=2.00$

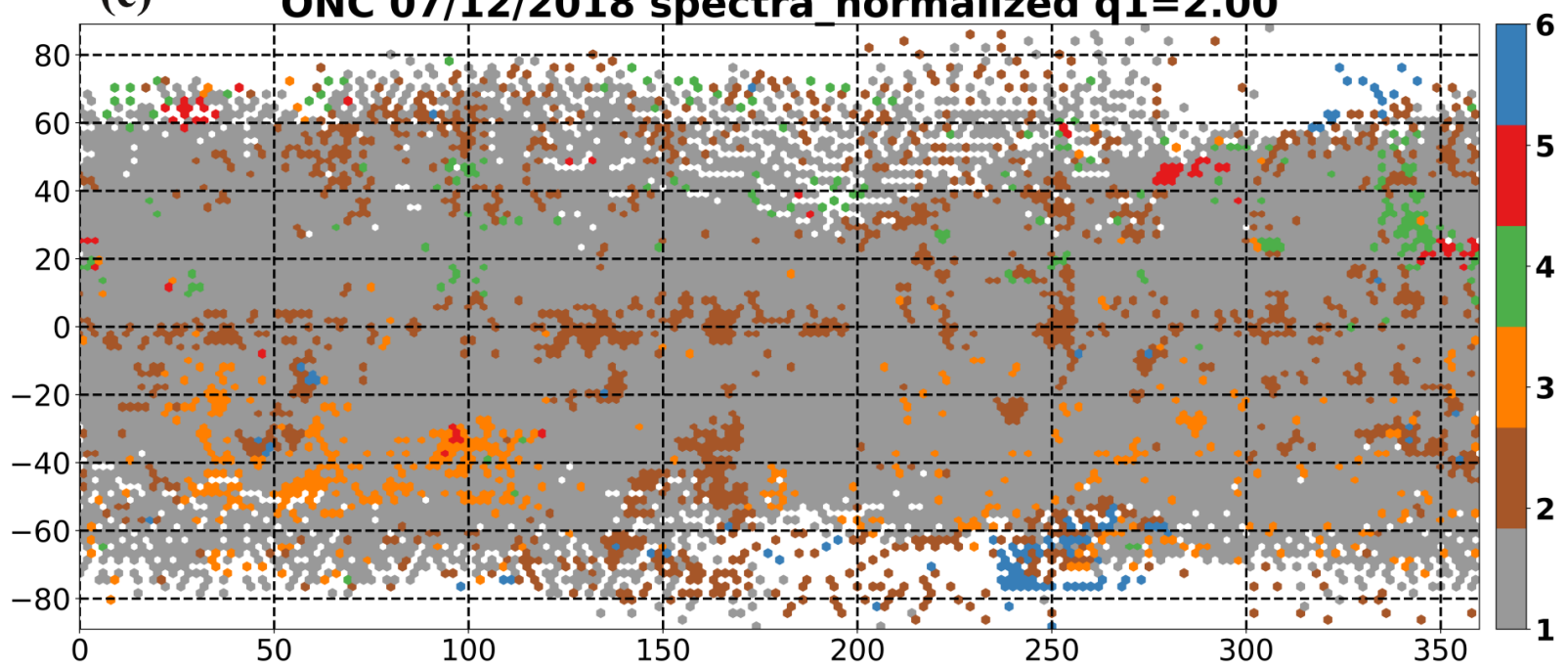

Fig. 2. Cylindrical projection map of surface of Ryugu. Panel $a$ : distribution of the two groups obtained at $3 \sigma$ confidence level; panel $b$ : surface map with crater and feature names generated from mosaicked $V$-band images as described by Sugita et al. (2019); and panel $c$ : distribution of the six groups obtained at $2 \sigma$ confidence level. 
A\&A 629, A13 (2019)

Table 2. Mean values of the reflectance normalized at $2001 \mathrm{~nm}$ and standard deviation for 24 NIRS3 wavelengths of the groups obtained at both confidence level values ( $3 \sigma$ and $2 \sigma$ ) based on the analyzed NIRS3 data of July 19, 2018.

\begin{tabular}{|c|c|c|c|c|c|c|c|}
\hline Confidence level & $3 \sigma$ & $3 \sigma$ & $2 \sigma$ & $2 \sigma$ & $2 \sigma$ & $2 \sigma$ & $2 \sigma$ \\
\hline Groups & $\# 1$ & $\# 2$ & $\# 1$ & $\# 2$ & $\# 3$ & $\# 4$ & \# 5 \\
\hline Numbers of sample & 12994 & 307 & 11207 & 1387 & 363 & 271 & 111 \\
\hline \multicolumn{8}{|l|}{ Wavelength (nm) } \\
\hline 1928.7 & $\begin{array}{l}0.993 \\
\pm 0.004 \\
\end{array}$ & $\begin{array}{l}0.993 \\
\pm 0.004 \\
\end{array}$ & $\begin{array}{l}0.993 \\
\pm 0.003 \\
\end{array}$ & $\begin{array}{l}0.993 \\
\pm 0.004 \\
\end{array}$ & $\begin{array}{l}0.993 \\
\pm 0.004 \\
\end{array}$ & $\begin{array}{l}0.992 \\
\pm 0.003 \\
\end{array}$ & $\begin{array}{l}0.993 \\
\pm 0.005 \\
\end{array}$ \\
\hline 2055.8 & $\begin{array}{l}1.028 \\
\pm 0.004\end{array}$ & $\begin{array}{l}1.031 \\
\pm 0.004\end{array}$ & $\begin{array}{l}1.028 \\
\pm 0.004\end{array}$ & $\begin{array}{l}1.030 \\
\pm 0.004\end{array}$ & $\begin{array}{l}1.030 \\
\pm 0.004\end{array}$ & $\begin{array}{l}1.025 \\
\pm 0.004\end{array}$ & $\begin{array}{l}1.031 \\
\pm 0.004\end{array}$ \\
\hline 2182.4 & $\begin{array}{l}1.032 \\
\pm 0.005\end{array}$ & $\begin{array}{l}1.040 \\
\pm 0.005\end{array}$ & $\begin{array}{l}1.031 \\
\pm 0.004\end{array}$ & $\begin{array}{l}1.037 \\
\pm 0.004\end{array}$ & $\begin{array}{l}1.039 \\
\pm 0.005\end{array}$ & $\begin{array}{l}1.025 \\
\pm 0.004\end{array}$ & $\begin{array}{l}1.041 \\
\pm 0.006\end{array}$ \\
\hline 2308.5 & $\begin{array}{l}1.054 \\
\pm 0.007\end{array}$ & $\begin{array}{l}1.071 \\
\pm 0.005\end{array}$ & $\begin{array}{l}1.053 \\
\pm 0.006\end{array}$ & $\begin{array}{l}1.064 \\
\pm 0.005\end{array}$ & $\begin{array}{l}1.069 \\
\pm 0.005\end{array}$ & $\begin{array}{l}1.042 \\
\pm 0.004\end{array}$ & $\begin{array}{l}1.075 \\
\pm 0.007\end{array}$ \\
\hline 2434.2 & $\begin{array}{l}1.089 \\
\pm 0.011\end{array}$ & $\begin{array}{l}1.120 \\
\pm 0.006 \\
\end{array}$ & $\begin{array}{l}1.087 \\
\pm 0.008\end{array}$ & $\begin{array}{l}1.107 \\
\pm 0.006 \\
\end{array}$ & $\begin{array}{l}1.118 \\
\pm 0.006\end{array}$ & $\begin{array}{l}1.069 \\
\pm 0.005\end{array}$ & $\begin{array}{l}1.130 \\
\pm 0.008 \\
\end{array}$ \\
\hline 2559.4 & $\begin{array}{l}1.116 \\
\pm 0.016\end{array}$ & $\begin{array}{l}1.162 \\
\pm 0.008\end{array}$ & $\begin{array}{l}1.113 \\
\pm 0.012\end{array}$ & $\begin{array}{l}1.142 \\
\pm 0.007\end{array}$ & $\begin{array}{l}1.159 \\
\pm 0.007\end{array}$ & $\begin{array}{l}1.087 \\
\pm 0.006\end{array}$ & $\begin{array}{l}1.177 \\
\pm 0.012\end{array}$ \\
\hline 2612.8 & $\begin{array}{l}1.125 \\
\pm 0.017\end{array}$ & $\begin{array}{l}1.175 \\
\pm 0.009\end{array}$ & $\begin{array}{l}1.120 \\
\pm 0.013\end{array}$ & $\begin{array}{l}1.152 \\
\pm 0.008\end{array}$ & $\begin{array}{l}1.171 \\
\pm 0.008\end{array}$ & $\begin{array}{l}1.091 \\
\pm 0.006\end{array}$ & $\begin{array}{l}1.192 \\
\pm 0.013\end{array}$ \\
\hline 2630.7 & $\begin{array}{l}1.103 \\
\pm 0.017\end{array}$ & $\begin{array}{l}1.154 \\
\pm 0.008\end{array}$ & $\begin{array}{l}1.100 \\
\pm 0.013\end{array}$ & $\begin{array}{l}1.152 \\
\pm 0.008\end{array}$ & $\begin{array}{l}1.150 \\
\pm 0.008\end{array}$ & $\begin{array}{l}1.074 \\
\pm 0.007\end{array}$ & $\begin{array}{l}1.170 \\
\pm 0.011\end{array}$ \\
\hline 2648.5 & $\begin{array}{l}1.090 \\
\pm 0.016\end{array}$ & $\begin{array}{l}1.139 \\
\pm 0.008\end{array}$ & $\begin{array}{l}1.087 \\
\pm 0.012\end{array}$ & $\begin{array}{l}1.117 \\
\pm 0.008\end{array}$ & $\begin{array}{l}1.135 \\
\pm 0.007\end{array}$ & $\begin{array}{l}1.063 \\
\pm 0.006\end{array}$ & $\begin{array}{l}1.155 \\
\pm 0.012\end{array}$ \\
\hline 2666.3 & $\begin{array}{l}1.090 \\
\pm 0.015\end{array}$ & $\begin{array}{l}1.137 \\
\pm 0.008\end{array}$ & $\begin{array}{l}1.087 \\
\pm 0.012\end{array}$ & $\begin{array}{l}1.116 \\
\pm 0.008\end{array}$ & $\begin{array}{l}1.133 \\
\pm 0.008\end{array}$ & $\begin{array}{l}1.064 \\
\pm 0.006\end{array}$ & $\begin{array}{l}1.152 \\
\pm 0.010\end{array}$ \\
\hline 2684.0 & $\begin{array}{l}1.187 \\
\pm 0.016\end{array}$ & $\begin{array}{l}1.135 \\
\pm 0.009\end{array}$ & $\begin{array}{l}1.084 \\
\pm 0.012\end{array}$ & $\begin{array}{l}1.114 \\
\pm 0.008\end{array}$ & $\begin{array}{l}1.130 \\
\pm 0.008\end{array}$ & $\begin{array}{l}1.061 \\
\pm 0.007\end{array}$ & $\begin{array}{l}1.152 \\
\pm 0.011\end{array}$ \\
\hline 2671.8 & $\begin{array}{l}1.040 \\
\pm 0.015\end{array}$ & $\begin{array}{l}1.085 \\
\pm 0.010 \\
\end{array}$ & $\begin{array}{l}1.037 \\
\pm 0.012 \\
\end{array}$ & $\begin{array}{l}1.165 \\
\pm 0.009 \\
\end{array}$ & $\begin{array}{l}1.082 \\
\pm 0.009\end{array}$ & $\begin{array}{l}1.014 \\
\pm 0.007\end{array}$ & $\begin{array}{l}1.102 \\
\pm 0.013 \\
\end{array}$ \\
\hline 2719.6 & $\begin{array}{l}0.997 \\
\pm 0.015\end{array}$ & $\begin{array}{l}1.040 \\
\pm 0.010\end{array}$ & $\begin{array}{l}0.994 \\
\pm 0.012\end{array}$ & $\begin{array}{l}1.020 \\
\pm 0.009\end{array}$ & $\begin{array}{l}1.036 \\
\pm 0.010\end{array}$ & $\begin{array}{l}0.969 \\
\pm 0.008\end{array}$ & $\begin{array}{l}1.055 \\
\pm 0.013\end{array}$ \\
\hline 2737.3 & $\begin{array}{l}1.027 \\
\pm 0.017\end{array}$ & $\begin{array}{l}1.078 \\
\pm 0.011\end{array}$ & $\begin{array}{l}1.024 \\
\pm 0.014\end{array}$ & $\begin{array}{l}1.055 \\
\pm 0.010\end{array}$ & $\begin{array}{l}1.073 \\
\pm 0.011\end{array}$ & $\begin{array}{l}0.995 \\
\pm 0.008\end{array}$ & $\begin{array}{l}1.096 \\
\pm 0.013\end{array}$ \\
\hline 2755.1 & $\begin{array}{l}1.080 \\
\pm 0.020\end{array}$ & $\begin{array}{l}1.139 \\
\pm 0.012 \\
\end{array}$ & $\begin{array}{l}1.077 \\
\pm 0.016\end{array}$ & $\begin{array}{l}1.113 \\
\pm 0.010 \\
\end{array}$ & $\begin{array}{l}1.135 \\
\pm 0.010\end{array}$ & $\begin{array}{l}1.043 \\
\pm 0.009\end{array}$ & $\begin{array}{l}1.161 \\
\pm 0.015 \\
\end{array}$ \\
\hline 2772.8 & $\begin{array}{l}1.103 \\
\pm 0.022\end{array}$ & $\begin{array}{l}1.166 \\
\pm 0.011\end{array}$ & $\begin{array}{l}1.100 \\
\pm 0.017\end{array}$ & $\begin{array}{l}1.139 \\
\pm 0.011\end{array}$ & $\begin{array}{l}1.161 \\
\pm 0.011\end{array}$ & $\begin{array}{l}1.062 \\
\pm 0.010\end{array}$ & $\begin{array}{l}1.189 \\
\pm 0.017\end{array}$ \\
\hline 2790.5 & $\begin{array}{l}1.073 \\
\pm 0.020\end{array}$ & $\begin{array}{l}1.130 \\
\pm 0.012\end{array}$ & $\begin{array}{l}1.069 \\
\pm 0.016\end{array}$ & $\begin{array}{l}1.105 \\
\pm 0.011\end{array}$ & $\begin{array}{l}1.126 \\
\pm 0.011\end{array}$ & $\begin{array}{l}1.037 \\
\pm 0.009\end{array}$ & $\begin{array}{l}1.150 \\
\pm 0.015\end{array}$ \\
\hline 2808.2 & $\begin{array}{l}1.060 \\
\pm 0.017\end{array}$ & $\begin{array}{l}1.110 \\
\pm 0.011 \\
\end{array}$ & $\begin{array}{l}1.057 \\
\pm 0.014 \\
\end{array}$ & $\begin{array}{l}1.087 \\
\pm 0.011 \\
\end{array}$ & $\begin{array}{l}1.106 \\
\pm 0.011 \\
\end{array}$ & $\begin{array}{l}1.032 \\
\pm 0.009\end{array}$ & $\begin{array}{l}1.126 \\
\pm 0.013 \\
\end{array}$ \\
\hline 2825.9 & $\begin{array}{l}1.083 \\
\pm 0.017\end{array}$ & $\begin{array}{l}1.139 \\
\pm 0.012\end{array}$ & $\begin{array}{l}1.080 \\
\pm 0.015\end{array}$ & $\begin{array}{l}1.114 \\
\pm 0.011\end{array}$ & $\begin{array}{l}1.135 \\
\pm 0.011\end{array}$ & $\begin{array}{l}1.050 \\
\pm 0.010\end{array}$ & $\begin{array}{l}1.158 \\
\pm 0.013\end{array}$ \\
\hline 2843.6 & $\begin{array}{l}1.107 \\
\pm 0.020\end{array}$ & $\begin{array}{l}1.165 \\
\pm 0.013\end{array}$ & $\begin{array}{l}1.104 \\
\pm 0.016\end{array}$ & $\begin{array}{l}1.140 \\
\pm 0.012\end{array}$ & $\begin{array}{l}1.160 \\
\pm 0.011\end{array}$ & $\begin{array}{l}1.074 \\
\pm 0.010\end{array}$ & $\begin{array}{l}1.186 \\
\pm 0.016\end{array}$ \\
\hline 2861.3 & $\begin{array}{l}1.086 \\
\pm 0.017 \\
\end{array}$ & $\begin{array}{l}1.132 \\
\pm 0.012 \\
\end{array}$ & $\begin{array}{l}1.083 \\
\pm 0.014 \\
\end{array}$ & $\begin{array}{l}1.112 \\
\pm 0.011 \\
\end{array}$ & $\begin{array}{l}1.128 \\
\pm 0.011 \\
\end{array}$ & $\begin{array}{l}1.059 \\
\pm 0.010 \\
\end{array}$ & $\begin{array}{l}1.150 \\
\pm 0.014 \\
\end{array}$ \\
\hline 2879.0 & $\begin{array}{l}1.099 \\
\pm 0.018\end{array}$ & $\begin{array}{l}1.147 \\
\pm 0.013\end{array}$ & $\begin{array}{l}1.096 \\
\pm 0.015\end{array}$ & $\begin{array}{l}1.126 \\
\pm 0.011\end{array}$ & $\begin{array}{l}1.143 \\
\pm 0.012\end{array}$ & $\begin{array}{l}1.069 \\
\pm 0.010\end{array}$ & $\begin{array}{l}1.163 \\
\pm 0.014\end{array}$ \\
\hline 2896.7 & $\begin{array}{l}1.105 \\
\pm 0.019\end{array}$ & $\begin{array}{l}1.151 \\
\pm 0.016\end{array}$ & $\begin{array}{l}1.102 \\
\pm 0.017\end{array}$ & $\begin{array}{l}1.129 \\
\pm 0.015\end{array}$ & $\begin{array}{l}1.146 \\
\pm 0.015\end{array}$ & $\begin{array}{l}1.078 \\
\pm 0.013\end{array}$ & $\begin{array}{l}1.165 \\
\pm 0.017\end{array}$ \\
\hline 2914.3 & $\begin{array}{l}1.105 \\
\pm 0.018\end{array}$ & $\begin{array}{l}1.153 \\
\pm 0.013\end{array}$ & $\begin{array}{l}1.102 \\
\pm 0.015\end{array}$ & $\begin{array}{l}1.133 \\
\pm 0.012\end{array}$ & $\begin{array}{l}1.149 \\
\pm 0.012\end{array}$ & $\begin{array}{l}1.078 \\
\pm 0.011\end{array}$ & $\begin{array}{l}1.171 \\
\pm 0.015\end{array}$ \\
\hline
\end{tabular}

Notes. The number of sample for each group is also reported.

A13, page 6 of 10 

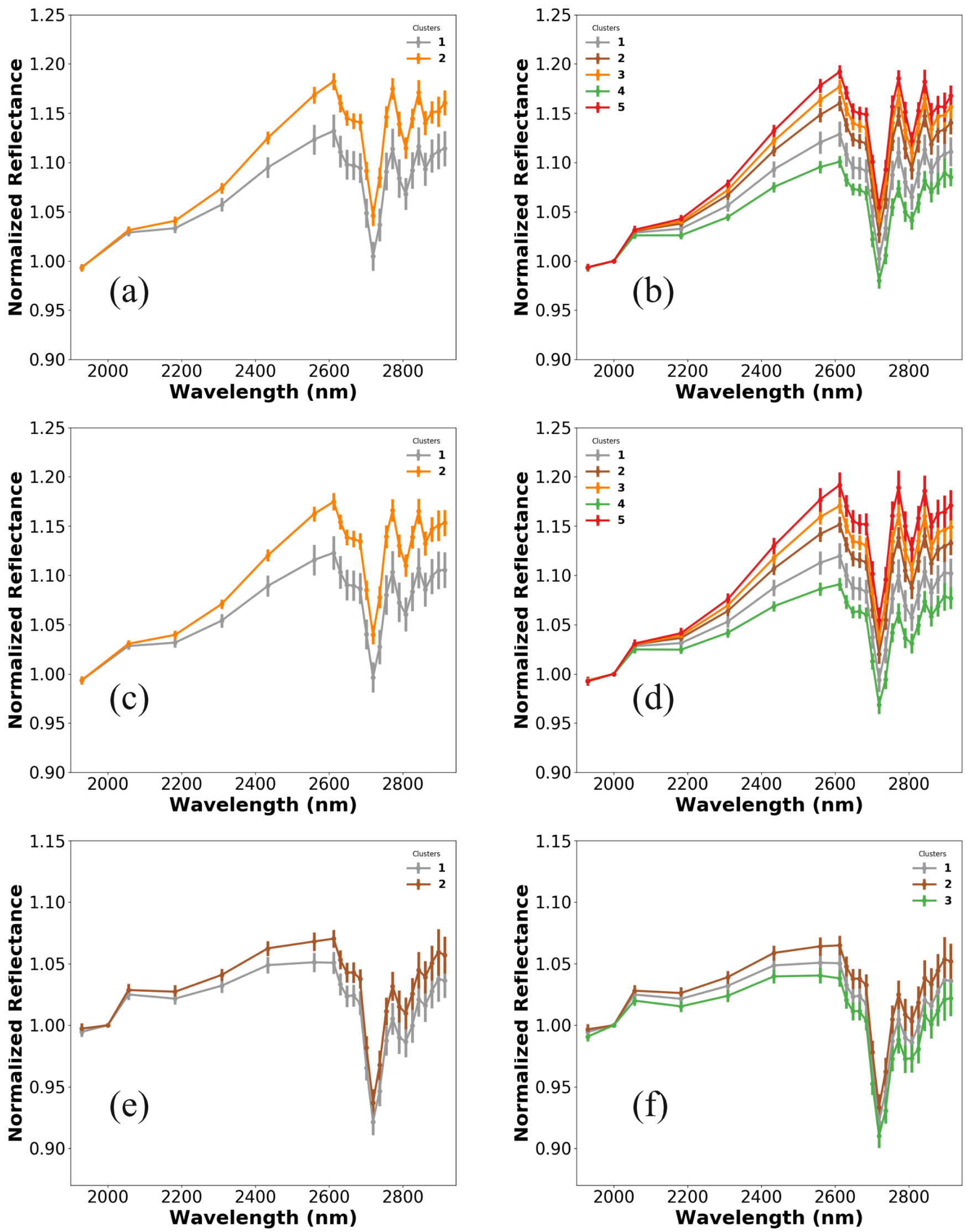

Fig. 3. Spectral groups obtained with analysis of $3 \sigma$ (left) and $2 \sigma$ (right) for 8300 NIRS3 spectra of July 11, 2018 ( $a$ and $b$ ), for 13385 NIRS3 spectra of July 19, $2018(c$ and $d$ ), and 16528 NIRS3 spectra of October 30, 2018 ( $e$ and $f$ ). The observations were carried out at different phase angles: $18.2^{\circ}$ for July $11 ; 17.5-17.8^{\circ}$ for July 19 ; and $7.6-7.8^{\circ}$ for October $30,2018$. 

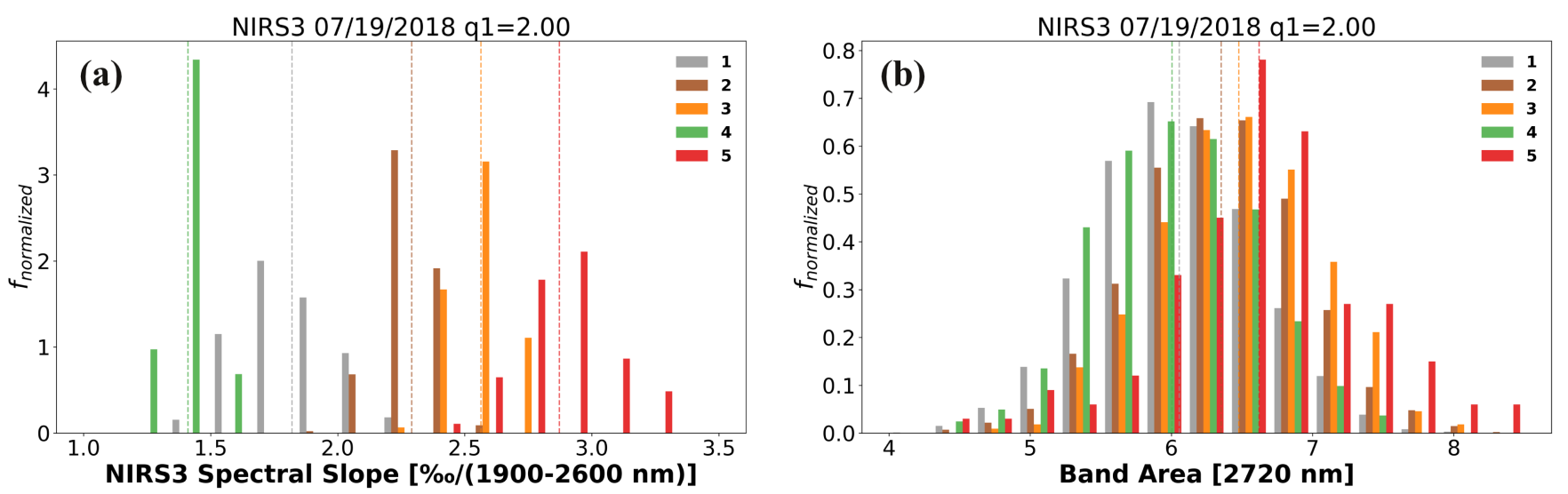

Fig. 4. Distribution of slope (left) and band area (right) of mean spectrum obtained for each of five groups based on analysis corresponding to $2 \sigma$ of July 19 NIRS3 data. The color code is the same as in Figs. 3d and $5 \mathrm{~d}$.

with the other data sets at the same confidence level. The larger group contains most of the objects, and the smallest group $(<2 \%)$ is redder than the larger one. At the $2 \sigma$, we found three groups (containing respectively the $91,6.4$, and $2.6 \%$ of objects), the former two have the same spectral characteristics of the previous ones, while the third is less red. The lower number of classes is a consequence of the reduced coverage and different resolution used during the spectroscopic observations of October 30, 2018.

\subsection{NIRS3 map groups distribution}

In the maps in Fig. 5 we report the various distributions of the groups obtained from NIRS3 data analysis based on different data sets of July 11 and 19, and October 30 at the two confidence levels $3 \sigma$ and $2 \sigma$. The groups obtained for July 11 and 19 are, at both confidence levels, similar in spectral behaviors with similar distribution on the map. At $3 \sigma$ the first group covers the majority of the surface and the second being smaller, covers less than $3 \%$ of the map (Figs. 5a and c). The two maps of July 11 and 19 are almost identical, even if the spectra correspond to a different spatial resolution $R=40 \mathrm{~m} \mathrm{px}^{-1}$ for July 11 , and $R=20 \mathrm{~m} \mathrm{px}^{-1}$ for July 19, 2018.

A finer subdivision is obtained when the confidence level is decreased to $2 \sigma$. Five groups are separated with the first, which covers the majority of the surface. The reddest groups (\#2, \#3, and \#5, reported in Fig. 5b, and Fig. 5d in brown, orange and red respectively) are in the same area of those reported in red and orange by the ONC-T data analysis (despite being at a different resolution), particularly in the western and southern areas. Group \#5 (Figs. 5b and d) is concentrated on the Ejima Saxum and on certain other larger boulders. Group \#4 is concentrated on the northern hemisphere, an area characterized by the quasi-circular depressions, as described by Sugita et al. (2019).

Comparing the obtained results with those of October 30 when the Hayabusa2 spacecraft was much closer and the spatial resolution of the obtained spectra was about $10 \mathrm{mpx}^{-1}$, the same results are obtained at $3 \sigma$ confidence level with the two groups (Fig. 5e). However, at $2 \sigma$ only three classes are obtained (Fig. 5f): group \#2 with its redder spectra is almost concentrated in the same areas (west and south) as the previous NIRS3 data analyzed, while group \#3 with its bluer spectra appears in different areas around the equatorial surface. The phase angle of these observations was smaller then the previous one from July, but no effect has been detected on spectral slope variations with changes of phase angles. This is in good agreement with
Perna et al. (2018) who found, on the basis of a large asteroid observational survey, that the effect of phase reddening on low-albedo asteroid spectra is negligible.

The analysis of the higher resolution data also shows a dichotomy between eastern and western hemispheres (Fig. 5f), as detected by Sugita et al. (2019). This might be associated with different grain sizes, and is also the case for northern and southern hemispheres. On the equatorial ridge, few different groups obtained at confidence level $2 \sigma$, are localized in small areas, and are less evident than those obtained at the same confidence level with the imaging data at visible wavelengths.

\section{Discussion}

The results that we obtained here using $G$-mode multivariate statistics at high confidence level $(3 \sigma)$ confirm general homogeneity of the surface composition. At this confidence level and using data obtained with ONC-T and NIRS3, only two classes are established with both instruments: one large and spread over about $97 \%$ of the observed surface and one much smaller. In the ONC-T data, the small group has a more flat/bluish spectrum than the large one (which is more red) and this can be associated with fresher material (Sugita et al. 2019) compared to the rest of the surface, which is more altered due to space weathering. In the NIRS3 data the small group which appears at $3 \sigma$ has more reddish spectra than the big group average spectrum. As the effect of space weathering on the wavelength range of 2000-3000 nm is less important than in the visible (Lantz et al. 2017); this is not surprising at these wavelengths. Only a limited part of the surface is associated with redder spectra.

Concerning the ONC-T data, at a lower confidence level of $2 \sigma$, six groups have been classified. Two groups (\#3 and \#5) have reddish spectra, while group \#6 is bluer and also corresponds to the higher albedo together with groups \#4 and \#2. The two groups with bluish spectra (\#6 and \#2) have high albedo compared to the others. The mean values of the albedos and the relative standard deviation is reported for each obtained group in Table 1. Some slight differences (albedo and slope) that were detected in groups (\#2 and \#6) and that are present in the equatorial ridge or in some other specific areas could be connected to fresh/more young materials. This may be the case even if the laboratory experiments by Lantz et al. $(2015,2017)$ carried out on carbonaceous chondrite meteorites do not allow clear conclusions to be drawn on the nature of space weathering on Ryugu. The small variations on the different groups obtained with 

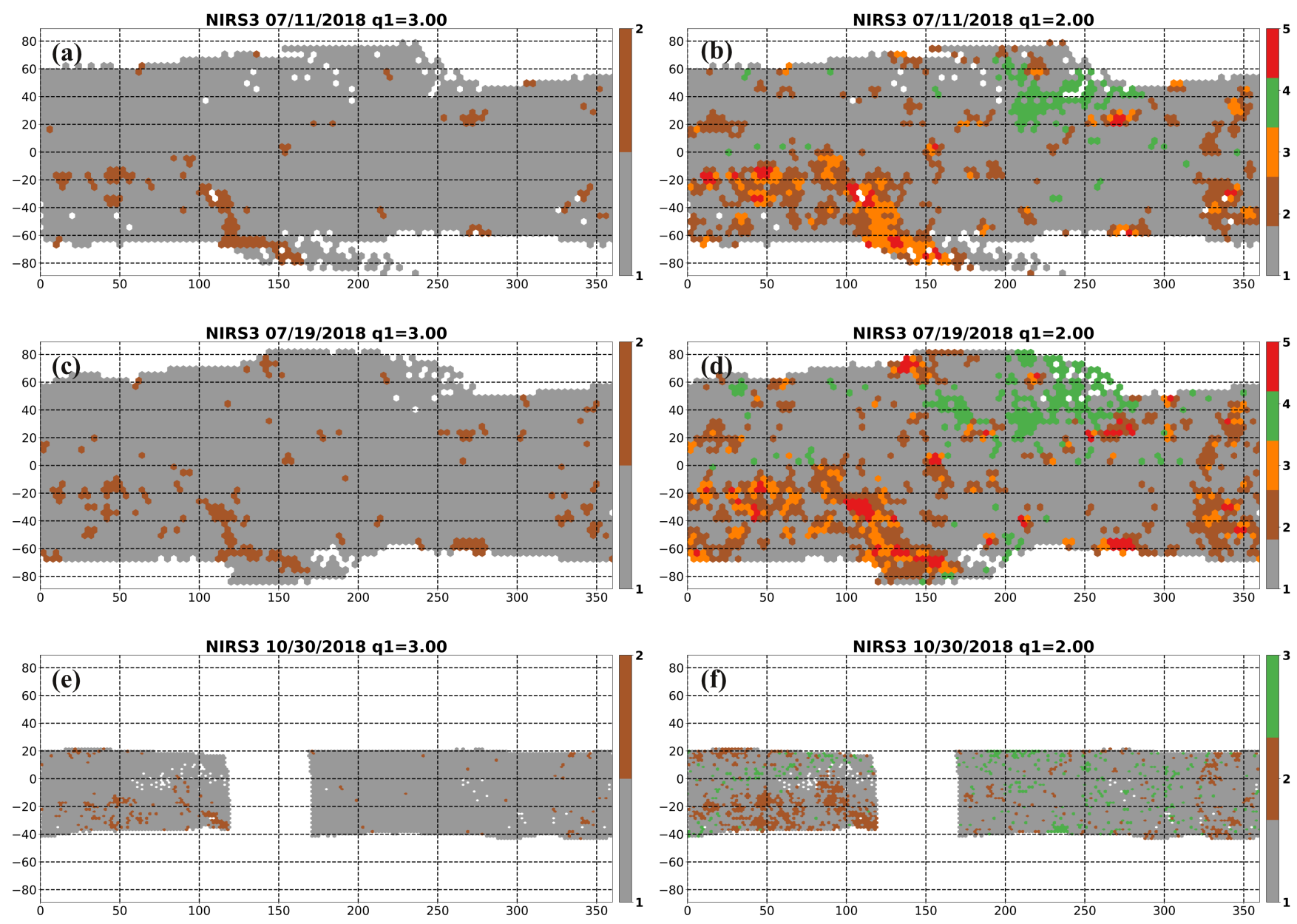

Fig. 5. Distribution of groups identified by analysis of NIRS3 data on cylindrical projection maps. Left panels: distribution of the two groups obtained at $3 \sigma$ confidence level; right panels: distribution of the various groups obtained at $2 \sigma$ confidence level. Distribution maps of the groups obtained for July 11, 2018 are in $(a)$ and $(b) ;(c)$ and $(d)$ are the distribution maps of the groups obtained for July 19, 2018; and $(e)$ and $(f)$ are the distribution maps of the groups obtained for October 30, 2018. The spatial resolutions are 40, 20, and less than $10 \mathrm{~m} \mathrm{px}^{-1}$, respectively. Group \#4 reported in green in panels $b$ and $d$ could be affected by uncertainties of thermal correction.

ONC-T data could be also related to different grain size distributions of regolith on the equatorial ridge or in the interior of some craters. Group \#2 (Fig. 2c) is more concentrated in Tokoyo Fossa, on the equatorial ridge, and on some localized specific areas such as impact craters, while group \#6 is located in Otohime Saxum, a boulder that could represent much more fresh materials. The redder groups \#3 and \#5 (Fig. 2c) are more concentrated on the proximity of Ejima Saxum and on the areas where large boulders are abundant, but probably are covered by fine regolith.

In the near-infrared wavelength for the NIRS3 data analysis, the surface of Ryugu is less covered and the data are acquired at lower spatial resolution than the visible wavelength by ONC-T data. The differences among the obtained five groups (Figs. 3b and d) are associated essentially with the differences in slopes between 2000 and $2600 \mathrm{~nm}$ (Fig. 4a) and in the areas of the $2720 \mathrm{~nm}$ bands (Fig. 4b). The reddest spectral groups (\#2, \#3, and \#5 in Figs. $3 \mathrm{~b}$ and $\mathrm{d}$ ) represent some areas with large boulders and areas inside a few specific craters like Momotaro, Kibidango, Urashima, and Cendrillon. These red slopes could be attributed to the presence of small sized regolith grains. From laboratory experiments on carbonaceous chondrite meteorites, the slope of the spectra changes in function of the grain sizes. Cloutis et al. (2018) examined how particle size and particle packing affect the reflectance spectra of carbonaceous meteorites: as the grain size of a powdered sample decreases the reddening of the spectral slope increases, even if the spectral slope may also depend on the compactness of the surface material. These effects on the spectral slope are higher in the near infrared than in the visible part of the spectra. Group \#4, concentrated in the north-eastern hemisphere, shows bluer spectra in the near infrared. This result could be affected by uncertainties of thermal correction, in fact at the time of these observations, the Sun was located in the southern side of Ryugu and the area corresponding to group \#4 (in Figs. 5b and d) was at lower temperature. No shift was detected to the center of the band at $2720 \mathrm{~nm}$ on all analyzed data. This difference from the 2720 $\mathrm{nm}$ band area (Fig. 4b) could be attributed to different content of phyllosilicates, nevertheless grain size and porosity are also important parameters that could change the spectral slope and band depth. One small variation is also found on the band at $2808 \mathrm{~nm}$. If this is real, this could be associated with different content of absorbed water or other unknown modes of hydroxyl absorption. Nevertheless, we have to underline the fact that the analysis of features and spectral variations at the limb or in the shadows is not evident. Differential movements introduce imperfect coregistering. Shaded areas remain as regions with higher calibration residuals for spectrophotometry. The spectroscopy should also be considered with some caveats to account for uncertainties remaining in the element-to element radiometric calibration (Kitazato et al. 2019). 


\section{Conclusions}

The combined analysis of both ONC-T and NIRS3 data allows us to characterize spectral properties of the major morphological surface features. We analyzed these data with the $G$-mode multivariate statistical analysis to detect very small surface variations. The statistical analysis of the spectrophotometry by ONC-T and NIRS3 spectral data at $3 \sigma$ confidence level clearly highlights a very homogeneous surface with slightly different small areas containing about $3 \%$ of the analyzed data. Decreasing the confidence level to $2 \sigma$, few small groups are detected with different average spectral slopes. The different groups obtained from NIRS3 spectral data show also differences in the area of the $2720 \mathrm{~nm}$ band that could be attributed to different content of hydrated phyllosilicates, nevertheless grain size and porosity are also important parameters that could change not only the spectral slopes but also the band depth.

From the results of the multivariate statistical analysis on Ryugu spectral (visible and near-infrared) data, we confirm small spectral variations characterized by the detection of different groups, increasing with the decrease of confidence levels. These small variations, characteristic of the various obtained groups, confirm a homogeneous object with the possibility of (i) slightly different content of hydrated phylossilicates; (ii) the presence of fresh material, less altered by space weathering; and (iii) different regolith sizes. Some younger surfaces that appeared around the equatorial ridge and on Otohime Saxum are different (also for the local albedo) from the rest of the surface as observed by spectrophotometric data. Unfortunately, NIRS3 observations do not cover the part of the surface closest to the pole. The areas that are supposed to be younger from the ONC-T analysis do not appear in the NIRS3 data analysis as the effect of space weathering is less important in the near-infrared wavelengths and the spatial resolution is lower. We suggest that the groups having redder spectra slopes, could also refer to surface zones with small sized regolith grains.

Moreover, the obtained results show a clear spectral dichotomy both between the eastern and western hemispheres and between the northern and southern hemispheres. From our results, the parts of surface represented in the maps with orange and red colors and localized on the southwestern hemisphere could be connected to the presence of small sized regolith grains. The former dichotomy is also discussed by Sugita et al. (2019) on the basis of the image geomorphological interpretation. The surface spectral variations we found here can give constrains on the re-accumulation phase of the present rubble-pile body after the catastrophic disruption of the parent asteroid (Michel et al. 2015).

Hayabusa2 is still working and some specific areas will have very detailed data both with ONC-T and NIRS3 instruments. We will also have imaging data of the sampling sites at very high resolution and more detailed analysis putting together available data of all the instruments will allow better interpretation of Ryugu's surface characteristics.

Acknowledgements. We thank the Haybusa2 JAXA team for their efforts in making the mission successful. Hayabusa2 was developed and built under the leadership of JAXA, with contributions from the DLR and the CNES, and in collaboration with NASA, Nagoya University, University of Tokyo, National Astronomical Observatory of Japan, Aizu University, Kobe University, and other universities, institutes, and companies in Japan. We would also wish to thank all the engineers who contributed to the success of the Hayabusa2 mission, especially T. Masuda, S. Yasuda, K. Matsushima, and T. Ohshima. This study was supported by JSPS International Planetary Network. M.A.B., P.H., J.D.P.D., and
M.F. acknowledge funding support from the CNES. D.P. has received funding from the European Union's Horizon 2020 research and innovation program under the Marie Sklodowska-Curie actions (grant agreement no. 664931).

\section{References}

Abramowitz, M., \& Stegun I. A. 1972, Handbook of Mathematical Functions (New York: Dover)

Bagrov, A. A. 1978, Tr. Gigronet Nauch. Issl. Zentra, 44, 3

Barucci, M. A., Capria, M., Coradini, A., et al. 1987, Icarus, 72, 304

Barucci, M. A., Belskaya, I. N., Fulchignoni, M., et al. 2005, AJ, 130, 1291

Belskaya, I., Barucci, M. A., Fulchignoni, M., et al. 2015, Icarus, 250, 482 Cloutis, E. A., Pietrasz, V. B., Kiddell, C., et al. 2018, Icarus, 305, 203

Coradini, A., Fulchignoni, M., Fanucci, O., \& Gavrishin, A. 1977, Comput. Geosci., 3, 85

Domingue, D., Tatsumi, E., Yokota, Y., et al. 2019, LPSC abstract, 2132

Fulchignoni, M., Birlain, M., Barucci, M. A., et al. 2000, Icarus, 146, 204

Gavrishin, A. I., Coradini, A., \& Cerroni, P. 1992, Earth Moon Planets, 59, 141

Hasselmann, P. H., Carvano, J. M., Lazzaro, D., et al. 2013, in Proc. of the 12th Python in Science Conference, eds. S. van der Walt, J. Millman, K. Hu, 53 Honda, R., Yokota, Y., Tatsumi , E., et al. 2018, 50th AAS-DPS, 411.109 Honda, R., Yokota, Y., Tatsumi, E., et al. 2019, LPSC abstract, 2901 Iwata, T., Kitazato, K., Abe, M., et al. 2017, Space Sci. Rev., 208, 317 Kameda, S., Suzuki, H., Takamatsu, T., et al. 2017, Space Sci. Rev., 208, 17 Keller, H. U., Barbieri, C., Lamy. P. L., et al. 2007, Space Sci. Rev., 128, 26 Kitazato, K., Milliken, R., Iwata, T., et al. 2019, Science, 364, 272 Lantz, C., Brunetto, R., Barucci, M. A., et al. 2015, A\&A, 577, A41 Lantz, C., Brunetto, R., Barucci, M. A., et al. 2017, Icarus, 285, 43

Leyrat, C., Fornasier, S., Barucci, M. A., et al. 2010, Planet. Space Sci., 58, 1097

Michel, P., Jutzi, D. C., Richardson, C. A., et al. 2015, Planet. Space Sci., 107, 24

Miller, R. L., \& Khan, J. S. 1962, Statistical Analysis in the Geological Science (New York: Wiley)

Perna, D., Fulchignoni, M., Barucci, M. A., et al. 2017, A\&A, 600, A115

Perna, D., Barucci, M. A., Fulchignoni, M., et al. 2018, Planet. Space Sci., 157, 82

Sugita, S., Honda, R., Morota, R., et al. 2019, Science, 364, 252

Suzuki, H., Yamada, T., Kouyama, E., et al. 2018, Icarus, 300, 341

Tatsumi, E., Kouyama, T., Suzuki, H., et al. 2019, Icarus, 325, 153

Watanabe, S., Hirabayashi, M., Hirata, N., et al. 2019, Science, 364, 268

Yabuta, H., Watanabe, S., Nakamura, T., et al. 2019, Lunar Planet. Sci. Conf., 2304

1 LESIA, Observatoire de Paris, PSL Research University, CNRS, Université Paris Diderot, Sorbonne Paris Cité, UPMC Université Paris 06, Sorbonne Universités, 5 place Jules Janssen, 92195 Meudon, France e-mail: antonella . barucci@obspm. fr

2 Kochi University, Kochi 780-8520, Japan

3 ISAS, JAXA, Sagamihara 252-5210, Japan

4 The University of Tokyo, Tokyo 113-0033, Japan

5 The University of Aizu, Aizu-Wakamatsu 965-8580, Japan

6 INAF, Osservatorio Astronomico di Roma, Monte Porzio Catone 00078, Italy

7 Nagoya University, Nagoya 464-8601, Japan

8 Rikkyo University, Tokyo 171-8501, Japan

9 Kwansei Gakuin University, Hyogo 662-8501, Japan

10 Brown University, Providence, RI 02912, USA

11 Tohoku University, Sendai 980-8578, Japan

12 AIST, Tokyo 135-0064, Japan

13 Meiji University, Kawasaki 214-8571, Japan

14 Chiba Institute of Technology, Narashino 275-0016, Japan

15 Kobe University, Kobe 657-8501, Japan

16 Jacobs/NASA Johnson Space Center, Houston, TX 77058, USA

17 Planetary Science Institute, Tucson, AZ 85719, USA

18 SOKENDAI (The Graduate University for Advanced Studies), Hayama 240-0193, Japan

19 Instituto de Astrofísica de Canarias, 38205 La Laguna, Spain 